\title{
Quantification of Phosphorylation of Insulin Receptor Substrate-1 by HPLC-ESI-MS/MS
}

\author{
Zhengping Yi, Moulun Luo, and Lawrence J. Mandarino* \\ School of Life Sciences, Arizona State University, Tempe, Arizona, USA
}

Sara M. Reyna

Department of Medicine, University of Texas Health Center at San Antonio, San Antonio, Texas, USA

\section{Christopher A. Carroll and Susan T. Weintraub}

Department of Biochemistry, University of Texas Health Science Center at San Antonio, San Antonio, Texas, USA

\begin{abstract}
Serine/threonine phosphorylation of insulin receptor substrate-1 (IRS-1) regulates the function and subsequent insulin signaling of this protein. Human IRS-1 has 1242 amino acid residues, including 182 serines and 60 threonines. The size, complexity, and relatively low abundance of this protein in biological samples make it difficult to map and quantify phosphorylation sites by conventional means. A mass spectrometry peak area based quantification approach has been developed and applied to assess the relative abundance of IRS-1 phosphorylation in the absence or presence of stimuli. In this method, the peak area for a phosphopeptide of interest is normalized against the average of peak areas for six selected representative IRS-1 peptides that serve as endogenous internal standards. Relative quantification of each phosphopeptide is then obtained by comparing the normalized peak area ratios for untreated and treated samples. Two non-IRS-1 peptides were added to each digest for use as HPLC retention time markers and additional standards as well as references to the relative quantity of IRS-1 in different samples. This approach does not require isotopic or chemical labeling and can be applied to various cell lines and tissues. Using this method, we assessed the relative changes in the quantities of two tryptic phosphopeptides isolated from human IRS-1 expressed in L6 cells incubated in the absence or presence of insulin or tumor necrosis factor- $\alpha$. Substantial increases of phosphorylation were observed for $\mathrm{Thr}^{446}$ upon stimulation. In contrast, no obvious change in the level of phosphorylation was observed for Ser ${ }^{1078}$. This mass spectrometry based strategy provides a powerful means to quantify changes in the relative phosphorylation of peptides in response to various stimuli in a complex, low-abundance protein. (J Am Soc Mass Spectrom 2006, 17, 562-567) (c) 2006 American Society for Mass Spectrometry
\end{abstract}

$\mathrm{I}$ nsulin receptor substrate-1 (IRS-1), a member of the IRS family proteins [1], plays a central role in insulin signaling. Tyrosine phosphorylation of IRS-1 by the insulin receptor is necessary for intracellular transduction of insulin signaling; however, serine/threonine phosphorylation also is involved in regulation of IRS-1 function [2]. Human IRS-1 has 1242 amino acid residues, including 182 serines and 60 threonines and is present at low abundance, even in cell cultures. As such, mapping and quantification of phosphorylation sites in IRS-1 by conventional means is an extremely difficult task. Approximately 40 serine/threonine phosphorylation sites have been identified from in vivo or in

Published online February 28, 2006

Address reprint requests to Dr. L. J. Mandarino, Department of Kinesiology, Arizona State University, P.O. Box 874501, Tempe, AZ 85287-4501, USA. E-mail: Lawrence.Mandarino@asu.edu

* Also affiliated with the Department of Kinesiology, Arizona State University, Tempe, Arizona vitro experiments, including 10 sites recently reported by our group [2-11], although the biological functions and relative quantification of most of these sites have not yet been elucidated.

IRS-1 has been found to be phosphorylated at multiple serine and threonine sites in the basal state [9]. After stimulation with insulin or tumor necrosis factor- $\alpha$ (TNF $\alpha$ ), the overall level of phosphorylation increases, as indicated by an upward shift in the migration of IRS-1 in polyacrylamide gels $[2,12]$. Because serine/threonine phosphorylation of IRS-1 is believed to play an important role in insulin resistance and type-2 diabetes mellitus [1, 13], relative quantification of IRS-1 phosphorylation under various conditions is important to provide insight into the molecular mechanism of insulin resistance. Site-specific quantification of IRS-1 phosphorylation has been carried out mainly by immunoblot analysis with specific antibodies against the phosphorylated site. However, only several such antibodies are commercially available, and genera- 
tion of new specific antibodies is difficult and time consuming. Mass spectrometry provides a more efficient and potentially more global way to identify and quantify phosphorylated residues in IRS-1.

The power of matrix-assisted laser desorption ionization time-of-flight mass spectrometry (MALDI-TOF/ MS) and high-performance liquid chromatography electrospray ionization tandem mass spectrometry (HPLC-ESI-MS/MS) as valuable tools to characterize post-translational modifications is widely recognized [14-18]. However, quantification of protein phosphorylation by mass spectrometry is still an analytical challenge $[19,20]$. There are a variety of approaches that have been employed for MS based quantification of protein phosphorylation, including the use of stable isotope labeled synthetic peptide analog internal standards [21, 22], metabolic labeling [23-26], derivatization [27-29], and evaluation of MS peak intensities of peptide(s) derived from proteins added before digestion [19] or from the protein of interest [20, 30]. Of particular note is the recent report by Steen and coworkers [20] in which normalization of phosphopeptides was made relative to "numerous" tryptic peptides from the target protein; peptides were selected for normalization based on a low relative deviation of signal intensity from the mean when evaluated in multiple experiments. Although the results obtained by that group were excellent in terms of reproducibility, a relatively large number of samples is required to generate the requisite dataset for curve fitting.

The use of peptides derived from the protein of interest for normalization to assess the levels of phosphorylation at specific sites offers clear advantages over other methods by accounting for differences in protein quantities among samples and by providing an accurate reflection of digestion efficiency. However, a key factor in this approach is the selection of peptides suitable for normalization. In the present report, we describe a straightforward strategy in which we utilized reproducibly-detected "representative" tryptic peptides that are distributed throughout the IRS-1 sequence for normalization to obtain relative quantities of specific phosphopeptides. In each sample, we also included two exogenous peptides to serve as additional standards and HPLC retention time markers. Using this approach, we assessed the effect of insulin or TNF $\alpha$ treatment of L6 cells on the relative phosphorylation at two sites in human IRS-1. The results show that insulin or TNF $\alpha$ can increase the relative degree of phosphorylation at $\mathrm{Thr}^{446}$ in IRS-1.

\section{Methods}

\section{Materials}

The following suppliers were used: PGEX-4T-3, Amersham (Piscataway, NJ); XL1-Blue, Stratagene (La Jolla, CA); glutathione-Sepharose beads, Amersham; sequencinggrade trypsin, Promega (Madison, WI); OMIX C18 tips (10 $\mu \mathrm{l})$, Varian (Lake Forest, CA); anti HA.11, Covance (Berke- ley, CA). L6 myoblasts cells were a gift from Dr. Amira Klip. The cDNA encoding full-length wild-type human IRS-1 was a gift from Dr. C. Ronald Kahn (Harvard University, MA).

\section{Adenoviruses}

Adenoviruses encoding green fluorescence protein (GFP, as an adenovirus control) and hIRS-1 were produced by using the AdEasy system (Quantum Biotechnologies, Montreal, Canada). The cDNA encoding HA-tagged hIRS-1 (pBEX-hIRS-1, prepared as previously described [10]) was cloned into the pAdTrack-CMV transfer vector using EcoR V and Xba I restriction sites. The hIRS-1-HA encoding sequence was then transferred into the pAdEasy viral DNA plasmid by homologous recombination in the BJ5183 Escherichia coli strain. The recombinant adenoviral construct was transfected in HEK293 cells to produce viral particles. Adenoviruses were purified by $\mathrm{CsCl}$ gradient centrifugation. The infection efficiency was estimated for GFP expression using an Olympus CK40 (Melville, NY) fluorescence microscope.

\section{Cell Culture, Transfection, Immunoprecipitation, and Western Blot Analysis}

L6 cells were grown in MEM medium (Gibco, Invitrogen, Carlsbad, CA), supplemented with $10 \%$ fetal bovine serum and $1 \%$ penicillin/streptomycin. For adenovirus experiments, cells were transduced with GFP (control) or hIRS-1 adenovirus (Ad-hIRS-1). After $36 \mathrm{~h}$ post-transfection/post-transduction, cells were serumstarved for 2 to $4 \mathrm{~h}$, treated with or without $100 \mathrm{nM}$ insulin $15 \mathrm{~min}$ or $10 \mathrm{nM} \mathrm{TNF} \alpha 30 \mathrm{~min}$, washed three times with ice-cold phosphate-buffered saline (PBS), and lysed in 300 to $400 \mu$ lof lysis buffer (50 mM HEPES, pH 7.6, $150 \mathrm{mM} \mathrm{NaCl}, 1 \%$ Triton X-100, $10 \mathrm{mM} \mathrm{NaF}, 20$ $\mathrm{mM}$ sodium pyrophosphate, $20 \mathrm{mM} \beta$-glycerol phosphate, $1 \mathrm{mM}$ sodium orthovanadate, $10 \mu \mathrm{g} / \mathrm{ml}$ leupeptin, $10 \mu \mathrm{g} / \mathrm{ml}$ aprotinin, $1 \mu \mathrm{m}$ microcystin-LR, and 1 $\mathrm{mM}$ phenylmethylsulfonyl fluoride). Cell lysates were centrifuged $\left(10,000 \times g, 4{ }^{\circ} \mathrm{C}, 10 \mathrm{~min}\right)$, and the clarified supernatants were used for immunoprecipitation. For immunoprecipitation, cell lysates were incubated with specific antibodies for 2 to $4 \mathrm{~h}$ on ice and then with protein G-agarose beads for 2 to $4 \mathrm{~h}$ at $4{ }^{\circ} \mathrm{C}$ with gentle rotation. Immunoprecipitates were washed extensively with ice-cold PTA buffer (PBS, pH 7.4, 0.5\% Tween 20, $0.05 \%$ SDS, $0.1 \%$ BSA, $0.02 \%$ sodium azide). Proteins bound to beads were eluted by heating at $95^{\circ} \mathrm{C}$ for 4 min in SDS sample loading buffer. Eluted proteins were separated by $10 \%$ SDS-PAGE and were stained with Coomassie blue.

\section{In-Gel Digestion}

The bands containing full-length IRS- 1 were excised,

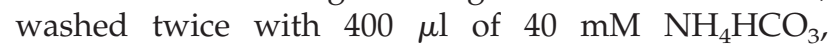


destained with $200 \mu \mathrm{l}$ of $50 \% \mathrm{ACN}$ in $40 \mathrm{mM}$ $\mathrm{NH}_{4} \mathrm{HCO}_{3}$, and dehydrated with $100 \% \mathrm{ACN}$ for $10 \mathrm{~min}$. ACN was removed, the gel pieces were dried in a vacuum centrifuge at $60^{\circ} \mathrm{C}$ for $8 \mathrm{~min}$, and digested in situ with $400 \mathrm{ng}$ trypsin (Promega) in $40 \mu \mathrm{l}$ of $40 \mathrm{mM}$ $\mathrm{NH}_{4} \mathrm{HCO}_{3}$ at $50{ }^{\circ} \mathrm{C}$ for $1 \mathrm{~h}$; the reactions were terminated by addition of $20 \mu \mathrm{l} \%$ TFA. After incubation at $37^{\circ} \mathrm{C}$ for $10 \mathrm{~min}$ and centrifugation for $1 \mathrm{~min}$, each supernatant was transferred to a clean tube. The extraction procedure was repeated after addition of $30 \mu \mathrm{l}$ of $0.1 \%$ TFA and the two extracts were combined. The resulting peptide mixtures were purified on OMIX C18 tips after sample loading in $0.1 \%$ TFA and elution with $50 \% \mathrm{ACN} / 0.1 \%$ TFA (vol/vol). The samples were concentrated to $\sim 1 \mu \mathrm{l}$ by vacuum centrifugation and $14 \mu \mathrm{l}$ of AngI/AngII ( $0.22 \mu \mathrm{M}$ each) in $0.1 \%$ TFA was added.

\section{Mass Spectrometry}

MALDI-TOF mass spectra were acquired on an Applied Biosystems Voyager-DE STR (Foster City, CA) in reflectron mode using dihydroxybenzoic acid as the matrix. HPLC-ESI-MS/MS was performed on a Thermo Finnigan LCQ (San Jose, CA) which has been adapted for microspray ionization. On-line HPLC separation of the IRS-1 digests was accomplished with a Michrom BioResources Paradigm MS4 micro HPLC: column, PicoFrit (New Objective, Woburn, MA; $75 \mu$ m i.d.) packed to 10 $\mathrm{cm}$ with C18 adsorbent (Vydac, Hesperia, CA; 218MSB5, $5 \mu \mathrm{m}, 300 \AA$ ) ; mobile phase, linear gradient of 2 to $65 \%$ acetonitrile (ACN) in $0.5 \%$ acetic acid $/ 0.005 \%$ trifluoroacetic acid (TFA) for $30 \mathrm{~min}$, a hold of $10 \mathrm{~min}$ at $65 \% \mathrm{ACN}$, and then a step to $80 \% \mathrm{ACN}$, hold $15 \mathrm{~min}$; flow rate, $0.4 \mu \mathrm{l} / \mathrm{min}$. Each digest was analyzed by MALDI-TOF/MS with database analysis by Mascot (Matrix Science, London, U.K.) to verify protein identity before HPLC-ESI-MS/MS. Our protocol for "top-4" data-dependent tandem MS analysis included acquisition of a full scan spectrum followed by collisioninduced dissociation mass spectra of the four most abundant ions in the survey scan. For some analyses, the survey scan covered a mass range of $m / z 300$ to 2000; for other experiments, a sample was injected twice, using ranges of $\mathrm{m} / \mathrm{z} 300$ to 900 , and 900 to 2000 to maximize the coverage of IRS-1. Additional scan strategies were subsequently utilized for the relative quantification analyses, as described in the Results and Discussion section. All uninterpreted tandem MS data were searched using Mascot. Assignments of the phosphopeptides were confirmed by manual comparison of the tandem mass spectra with the predicted fragmentation generated in silico by GPMAW (Lighthouse Data, Odense, Denmark) and/or the MS-Product component of ProteinProspector (http:// prospector.ucsf.edu).

\section{Statistical Analyses}

Statistical significance was assessed by one-way analysis of variance (ANOVA) followed by pairwise compar-
Table 1. IRS-1 peptides used to assess relative quantification at specific phosphorylation sites

\begin{tabular}{llc}
\hline Residues & \multicolumn{1}{c}{ Sequence } & Molecular weight ${ }^{\mathrm{a}}(\mathrm{Da})$ \\
\hline \hline $29-33$ & FFVLR & 681.4 \\
$178-184$ & NLIGIYR & 848.5 \\
$573-580$ & HSAFVPTR & 914.5 \\
$639-651$ & SVSAPQQIINPIR & 1422.8 \\
$1017-1028$ & TGIAAEEVSLPR & 1242.7 \\
$1075-1081$ & VNLSPNR & 799.4 \\
Angl & DRVYIHPFHL & 1296.7 \\
Angll & DRVYIHPF & 1046.5 \\
\hline
\end{tabular}

${ }^{\mathrm{a}}$ Monoisotopic values

ison assessment by the Student-Newman-Keuls (SNK) test.

\section{Results and Discussion}

\section{Selection of Representative Peptides Derived from Human IRS-1}

Full-length human IRS-1 samples expressed in L6 cells were prepared in four independent experiments, and at least two HPLC-ESI-MS/MS analyses of each sample were performed using a standard "top- 4 " data-dependent scan strategy. MALDI-TOF/MS and HPLC-ESI-MS/MS analysis of the tryptic digests confirmed the presence of IRS-1 (40\% coverage; Sprot database analysis by Mascot). Based on results from these analyses, six "representative" IRS-1 peptides (Table 1) that were reproducibly detected in the tryptic digest were selected according to the following criteria: (1) detected by HPLC-ESI-MS with high intensity among IRS-1 peptides; (2) no missed cleavage observed; (3) no methionine in the sequence to avoid variability due to methionine oxidization; (4) distributed throughout the IRS-1 sequence.

\section{Identification and Relative Quantification of Phosphopeptides Derived from Human IRS-1}

During the course of our analyses of IRS-1 expressed in L6 cells, several phosphopeptides were identified and verified by targeted MS/MS. Analogous to our recent report on phosphorylation in IRS-1 expressed in HEK293 cells [10], in the current experiments we again identified Ser ${ }^{1078}$ in VNLpSPNR as a site of phosphorylation. The unphosphorylated counterpart of this peptide is one of the six representative IRS-1 peptides used as endogenous standards in these studies. In addition, $\mathrm{Thr}^{446}$ in SVPTPDSLGHTPPAR was identified as a novel phosphorylation site in IRS-1 expressed in L6 cells. Relative changes in the quantities of these two IRS-1 phosphopeptides were then assessed in response to stimuli, as described below.

IRS-1 was isolated from L6 cells that were either untreated or exposed to insulin or TNF $\alpha$ as described in Methods. Each tryptic digest was analyzed in quadruplicate by HPLC-ESI-MS/MS using a scan protocol 
Table 2. Relative quantification of phosphopeptides in IRS-1

\begin{tabular}{|c|c|c|c|c|c|c|c|c|}
\hline \multirow[t]{2}{*}{ Sample ${ }^{b}$} & \multicolumn{4}{|c|}{ Peak intensity ${ }^{a}$} & \multicolumn{2}{|c|}{$\begin{array}{l}\text { Relative to average } \\
\text { of six IRS-1 peptides }\end{array}$} & \multicolumn{2}{|c|}{$\begin{array}{l}\text { Relative } \\
\text { to Angll }\end{array}$} \\
\hline & Angll & Avg. of 6 IRS-1 pep. & IRS-1 ${ }^{1075-1081}$ & IRS-1444-457 & IRS-1 ${ }^{1075-1081}$ & IRS-1444-457 & IRS-1 ${ }^{1075-1081}$ & IRS-1444-457 \\
\hline \multicolumn{9}{|l|}{ Control } \\
\hline C1 & $2.31 \mathrm{E}+07$ & $2.25 \mathrm{E}+07$ & $2.65 E+06$ & $1.60 E+06$ & 0.12 & 0.08 & 0.11 & 0.07 \\
\hline C2 & $1.26 \mathrm{E}+08$ & $1.08 \mathrm{E}+08$ & $1.14 \mathrm{E}+07$ & $1.00 E+07$ & 0.11 & 0.09 & 0.09 & 0.08 \\
\hline C3 & $2.84 E+08$ & $3.10 E+08$ & $3.83 E+07$ & $1.79 E+07$ & 0.12 & 0.06 & 0.13 & 0.06 \\
\hline $\mathrm{C} 4$ & $1.17 E+08$ & $1.36 \mathrm{E}+08$ & $1.25 \mathrm{E}+07$ & $1.10 \mathrm{E}+07$ & 0.09 & 0.08 & 0.11 & 0.09 \\
\hline Mean \pm s.e. & & & & & $0.110 \pm 0.007$ & $0.076 \pm 0.007$ & $0.112 \pm 0.009$ & $0.076 \pm 0.007$ \\
\hline rel. quant. & & & & & 1.00 & 1.00 & 1.00 & 1.00 \\
\hline \multicolumn{9}{|l|}{ Insulin } \\
\hline 11 & $3.10 E+08$ & $2.88 \mathrm{E}+08$ & $3.36 \mathrm{E}+07$ & $3.35 E+07$ & 0.12 & 0.12 & 0.11 & 0.11 \\
\hline 12 & $1.23 E+08$ & $1.63 E+08$ & $1.90 \mathrm{E}+07$ & $2.00 E+07$ & 0.12 & 0.12 & 0.15 & 0.16 \\
\hline 13 & $7.96 \mathrm{E}+07$ & $1.06 \mathrm{E}+08$ & $1.28 \mathrm{E}+07$ & $1.90 \mathrm{E}+07$ & 0.12 & 0.18 & 0.16 & 0.24 \\
\hline 14 & $7.67 E+07$ & $8.02 \mathrm{E}+07$ & $8.80 \mathrm{E}+06$ & $1.05 E+07$ & 0.11 & 0.13 & 0.11 & 0.14 \\
\hline Mean \pm s.e. & & & & & $0.116 \pm 0.002$ & $0.137 \pm 0.014^{c}$ & $0.135 \pm 0.013$ & $0.162 \pm 0.028^{c}$ \\
\hline rel. quant. & & & & & 1.06 & 1.82 & 1.20 & 2.11 \\
\hline \multicolumn{9}{|l|}{ TNF $\alpha$} \\
\hline $\mathrm{T} 1$ & $8.22 \mathrm{E}+07$ & $7.35 \mathrm{E}+07$ & $1.14 \mathrm{E}+07$ & $9.00 E+06$ & 0.16 & 0.12 & 0.14 & 0.11 \\
\hline T2 & $1.47 E+08$ & $1.45 E+08$ & $1.57 E+07$ & $2.20 \mathrm{E}+07$ & 0.11 & 0.15 & 0.11 & 0.15 \\
\hline T3 & $1.97 E+08$ & $2.13 E+08$ & $2.26 \mathrm{E}+07$ & $3.20 E+07$ & 0.11 & 0.15 & 0.11 & 0.16 \\
\hline T4 & $1.69 \mathrm{E}+08$ & $1.79 E+08$ & $1.52 \mathrm{E}+07$ & $2.11 \mathrm{E}+07$ & 0.09 & 0.12 & 0.09 & 0.12 \\
\hline Mean \pm s.e. & & & & & $0.114 \pm 0.015$ & $0.136 \pm 0.009^{c}$ & $0.113 \pm 0.010$ & $0.137 \pm 0.012^{c}$ \\
\hline rel. quant. & & & & & 1.04 & 1.79 & 1.01 & 1.79 \\
\hline
\end{tabular}

${ }^{a}$ Combined peak areas for the $1+, 2+$, and $3+$ (when detected) charge states for each peptide were obtained by integration of the appropriate reconstructed ion chromatograms.

bIRS-1 was isolated by immunoprecipitation after expression in L6 cells, as described in Methods. After separation by 1-D SDS PAGE, the IRS-1 band was digested in situ by trypsin and analyzed by HPLC-ESI-MS/MS.

'Statistically significant difference $(P<0.05)$ compared to the corresponding control group as assessed by a 1 -way analysis of variance followed by assessment of pairwise comparisons by the Student-Newman-Keuls test.

consisting of one survey scan, one parent list MS/MS scan (with the $2+$ charge states of the six representative IRS-1 peptides included in the list), and two targeted MS/MS scans (for the 2+ ions of the phosphopeptides of interest). Combined peak areas for the $1+, 2+$, and $3+$ (when detected) charge states for each peptide were obtained by integration of the appropriate reconstructed ion chromatograms. Peak areas for AngI and AngII were also determined. The values obtained for the six IRS-1 peptides were summed and the average used for subsequent normalization of phosphopeptide peak areas. In all analyses, the tandem mass spectra obtained for each peptide of interest were used to verify identity. In Table 2 can be seen the average of the combined charge state peak areas for the six representative IRS-1 peptides and the phosphopeptides containing $\mathrm{Thr}^{446}$ and Ser ${ }^{1078}$ in addition to that for AngII. (Note that the results obtained when AngI was used as a reference were essentially the same as for AngII and are not included in the table.) The relatively low standard errors for the results in Table 2 demonstrate that use of the average of the combined peak areas for the six IRS-1 peptides was an effective way to normalize the intensity values for the phosphopeptides of interest to compensate for differences in sample quantity and injection volume.

As can be seen in Table 2, the normalized peak areas for the peptide containing Ser $^{1078}$ in IRS-1 (VNLpSPNR) isolated from insulin- or TNF $\alpha$-treated L6 cells were essentially the same as for VNLpSPNR obtained from untreated L6 cells: (control, $0.110 \pm 0.007$; insulintreated L6 cells, $0.116 \pm 0.002 ; \mathrm{TNF} \alpha$-treated L6 cells, $0.114 \pm 0.015)$, indicating that exposure to either insulin or TNF $\alpha$ did not affect the degree of phosphorylation at this site. In contrast, the results reveal that for $\mathrm{pThr} \mathrm{r}^{446}$ (in SVpTPDSLGHTPPAR) there was an $\sim 80 \%$ increase in the normalized peak area for IRS-1 peptides isolated from either insulin- or TNF $\alpha$-treated L6 cells compared to peptides obtained from untreated cells: (control, $0.076 \pm 0.007$; insulin-treated L6 cells, $0.137 \pm 0.014$; $\mathrm{TNF} \alpha$-treated L6 cells, $0.136 \pm 0.009$ ). The change in relative phosphorylation at this site induced by insulin or TNF $\alpha$ was found to be statistically significant by ANOVA with pairwise comparisons assessed by the Student-Newman-Keuls (SNK) test. A bar graph illustrating the effects of insulin and TNF $\alpha$ on phosphorylation at Ser ${ }^{1078}$ and $\mathrm{Thr}^{446}$ in IRS-1 is shown in Figure 1. It is important to note that when the ratios of the peak areas for the average of the six IRS- 1 peptides were compared to AngII, the following values were obtained: control L6 cells, $1.021 \pm 0.067$; insulin-treated L6 cells, $1.158 \pm 0.102 ; \mathrm{TNF} \alpha$-treated L6 cells, $1.005 \pm 0.042$. These results indicate that there were no substantial changes in the overall level of IRS-1 induced by treatment with either insulin or $\mathrm{TNF} \alpha$.

The results presented above demonstrate that HPLCESI-MS peak areas of selected endogenous peptides can be successfully used as internal standards to assess 


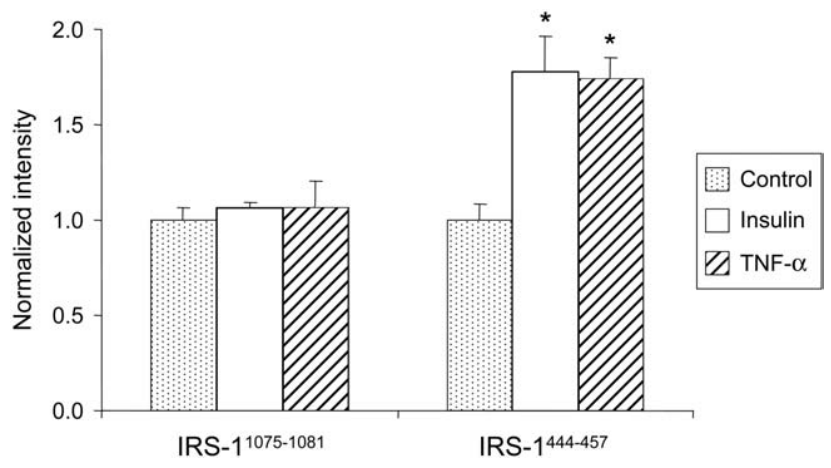

Figure 1. Relative quantification of phosphopeptides of IRS-1 expressed in L6 cells. Following treatment with insulin or TNF $\alpha$, IRS-1 was isolated by immunoprecipitation, as described in Methods. After separation by 1-D SDS PAGE, each IRS-1 band was digested in situ with trypsin and analyzed by HPLC-ESI-MS/MS. Normalization of peak areas for the phosphopeptides using 6 endogenous IRS-1 representative peptides was accomplished as described in Methods. Values represent the mean \pm standard error of the mean for 4 HPLC-ESI-MS/MS analyses of the same sample; asterisk, statistically significant difference $(P<.05)$ compared to the corresponding control group as assessed by a one-way analysis of variance followed by pairwise comparisons using the Student-Newman-Keuls test.

relative changes in target phosphopeptides in response to cellular stimuli such as insulin and TNF $\alpha$. Thr ${ }^{446}$ in SVpTPDSLGHTPPAR is a newly discovered phosphorylation site in IRS-1 expressed in L6 cells. After stimulation with either insulin or $\mathrm{TNF} \alpha$, phosphorylation at $\mathrm{Thr}^{446}$ was found to increase by $80 \%$. Ser ${ }^{1078}$ (in VNLpSPNR) is a phosphorylation site we have previously identified in IRS-1 expressed in HEK-293 cells [10]. In contrast to $\mathrm{Thr}^{446}$, we saw no changes in the relative degree of phosphorylation at this site upon stimulation with insulin or TNF $\alpha$. The unphosphorylated form of this peptide was used as one of the six representative IRS-1 peptides; the abundance of the unphosphorylated peptide also remained constant in the untreated and treated samples. It is important to note that the intensities of the variously-charged ions representing VNLSPNR were 8 to 10 times higher than the corresponding ions for VNLpSPNR, thereby making it possible to include VNLSPNR among the representative IRS-1 peptides used for normalization. In the event that there might be a high degree of phosphorylation at Ser ${ }^{1078}$, it would be necessary to either pick an alternative peptide from the C-terminal region of IRS-1 or else only use the other five peptides for normalization.

In the method described here, representative peptides derived from the protein of interest were used to normalize the phosphopeptide intensity data. As such, it was possible to directly assess relative changes in phosphorylation at targeted sites. The avoidance of methionine-containing sequences as well as peptides exhibiting missed tryptic cleavages helped to enhance the reproducibility of detection of the representative peptides. Moreover, selection of peptides distributed throughout the IRS-1 sequence gave a more global assessment of the digestion. And, by averaging the combined charge state peak areas for the six representative peptides in the control and experimental samples, it was possible to minimize differences in individual peptides.

An important aspect of our approach for relative quantification of phosphopeptides is that tandem mass spectra were acquired for all endogenous and phosphorylated peptides of interest to verify that the MS intensities being used were associated with the correct peptide. By using a combination of a parent list for the relatively intense representative IRS-1 peptides and a target scan list for the less intense phosphopeptides, we could be certain that all necessary tandem mass spectra would be acquired. Moreover, inclusion of AngI and AngII as reference standards made it possible to verify the analytical results for the IRS- 1 representative peptides and to assess the relative quantity of IRS- 1 in different samples.

A major advantage of the approach described here is that it does not require derivatization or isotopic labeling, thus minimizing sample processing and eliminating sources for potential experimental variation. In addition, this method can be applied to a wide variety of cell lines and tissues since metabolic labeling is not involved. In numerous reports in the literature, assessment of changes in phosphorylation has been made by immunoblot analysis. However there are no commercially available phospho-specific antibodies for many of the identified phosphorylation sites, such as $\mathrm{Thr}^{446}$ or Ser ${ }^{1078}$ in IRS-1. Use of the MS based strategy described here enabled us to evaluate relative changes in phosphorylation at these two IRS-1 sites in response to exposure of L6 cells to insulin or TNF $\alpha$. Experiments such as these are important for elucidating the functional consequences of phosphorylation at these sites in vivo and might lead to new insights into insulin resistance and type-2 diabetes. We are planning to apply this approach to the relative quantification of phosphorylation of IRS-1 in human muscle obtained from normal subjects and people with type-2 diabetes.

\section{Acknowledgments}

This work was supported in part by NIH grants R01DK47936 (LJM), R01DK66483 (LJM), and P30 CA54174-16 (STW). The MS analyses were conducted in the UTHSCSA Institutional Mass Spectrometry Laboratory.

\section{References}

1. White, M. F. IRS Proteins and the Common Path to Diabetes. Am. J. Physiol. Endocrinol. Metab. 2002, 283, E413-E422.

2. Gual, P.; Le Marchand-Brustel, Y.; Tanti, J. F. Positive and Negative Regulation of Insulin Signaling Through IRS-1 Phosphorylation. Biochimie 2005, 87, 99-109.

3. Gao, Z.; Zuberi, A.; Quon, M. J.; Dong, Z.; Ye, J. Aspirin Inhibits Serine Phosphorylation of Insulin Receptor Substrate 1 in Tumor Necrosis Factor-Treated Cells Through Targeting Multiple Serine Kinases. J. Biol. Chem. 2003, 278, 24944-24950.

4. Kim, J. A.; Yeh, D. C.; Ver, M.; Li, Y.; Carranza, A.; Conrads, T. P.; Veenstra, T. D.; Harrington, M. A.; Quon, M. J. Phosphorylation of Ser24 
in the Pleckstrin Homology Domain of Insulin Receptor Substrate-1 by Mouse Pelle-Like Kinase/Interleukin-1 Receptor-Associated Kinase: Cross-Talk Between Inflammatory Signaling and Insulin Signaling that May Contribute to Insulin Resistance. J. Biol. Chem. 2005, 280, 23173-23183.

5. Liu, Y. F.; Herschkovitz, A.; Boura-Halfon, S.; Ronen, D.; Paz, K.; Leroith, D; Zick, Y. Serine Phosphorylation Proximal to its Phosphotyrosine Binding Domain Inhibits Insulin Receptor Substrate 1 Function and Promotes Insulin Resistance. Mol. Cell. Biol. 2004, 24, 9668-9681.

6. Ozes, O. N.; Akca, H.; Mayo, L. D.; Gustin, J. A.; Maehama, T.; Dixon, J. E.; Donner, D. B. A phosphatidylinositol 3-kinase/Akt/mTOR pathway mediates and PTEN antagonizes tumor necrosis factor inhibition of insulin signaling through insulin receptor substrate-1. Proc. Natl. Acad. Sci. U.S.A. 2001. 98, 4640-4645.

7. Sommerfeld, M. R.; Metzger, S.; Stosik, M.; Tennagels, N.; Eckel, J. In Vitro Phosphorylation of Insulin Receptor Substrate 1 by Protein Kinase C-zeta: Functional Analysis and Identification of Novel Phosphorylation Sites. Biochemistry 2004, 43, 5888-5901.

8. Tanasijevic, M. J.; Myers, M. G., Jr.; Thoma, R. S.; Crimmins, D. L.; White, M. F.; Sacks, D. B. Phosphorylation of the Insulin Receptor Substrate IRS-1 by Casein Kinase II. J. Biol. Chem. 1993, 268, 1815718166.

9. Greene, M. W.; Garofalo, R. S. Positive and Negative Regulatory Role of Insulin Receptor Substrate 1 and 2 (IRS-1 and IRS-2) Serine/Threonine Phosphorylation. Biochemistry 2002, 41, 7082-7091.

10. Luo, M.; Reyna, S.; Wang, L.; Yi, Z.; Carroll, C.; Dong, L. O.; Langlais, P.; Weintraub, S. T.; Mandarino, L. J. Identification of IRS-1 Serine/ Threonine Phosphorylation Sites Using Mass Spectrometry Analysis. Regulatory Role of Serine 1223. Endocrinology 2005, 146, 4410-4416.

11. Yi, Z.; Luo, M.; Carroll, C. A.; Weintraub, S. T.; Mandarino, L. J. Identification of Phosphorylation Sites in Insulin Receptor Substrate-1 by Hypothesis-Driven High-Performance Liquid ChromatographyElectrospray Ionization Tandem Mass Spectrometry. Anal. Chem. 2005, 77, 5693-5699.

12. Egawa, K.; Nakashima, N.; Sharma, P. M.; Maegawa, H.; Nagai, Y.; Kashiwagi, A.; Kikkawa, R.; Olefsky, J. M. Persistent Activation of Phosphatidylinositol 3-Kinase Causes Insulin Resistance Due to Accelerated Insulin-Induced Insulin Receptor Substrate-1 Degradation in 3T3-L1 Adipocytes. Endocrinology 2000, 141, 1930-1935.

13. Zick, Y. Insulin Resistance: A Phosphorylation Based Uncoupling of Insulin Signaling. Trends Cell. Biol. 2001, 11, 437-441.

14. Giorgianni, F.; Beranova-Giorgianni, S.; Desiderio, D. M. Identification and Characterization of Phosphorylated Proteins in the Human Pituitary. Proteomics 2004, 4, 587-598.

15. Mann, M.; Ong, S. E.; Gronborg, M.; Steen, H.; Jensen, O. N.; Pandey, A. Analysis of Protein Phosphorylation Using Mass Spectrometry: Deciphering the phosphoproteome. Trends Biotechnol. 2002, 20, 261-268.

16. Jensen, O. N. Modification-Specific Proteomics: Characterization of Post-Translational Modifications by Mass Spectrometry. Curr. Opin. Chem. Biol. 2004, 8, 33-41.
17. Peters, E. C.; Brock, A.; Ficarro, S. B. Exploring the Phosphoproteome with Mass Spectrometry. Mini Rev. Med. Chem. 2004, 4, 313-324.

18. Gingras, A. C.; Aebersold, R.; Raught, B. Advances in Protein Complex Analysis Using Mass Spectrometry. J. Physiol. 2005, 563, 11-21.

19. Cutillas, P. R.; Geering, B.; Waterfield, M. D.; Vanhaesebroeck, B. Quantification of Gel-Separated Proteins and Their Phosphorylation Sites by LC-MS Using Unlabeled Internal Standards: Analysis of Phosphoprotein Dynamics in a B-Cell Lymphoma Cell Line. Mol. Cell. Proteom. 2005, 4, 1038-1051.

20. Steen, H.; Jebanathirajah, J. A.; Springer, M.; Kirschner, M. W. Stable Isotope-Free Relative and Absolute Quantitation of Protein Phosphorylation Stoichiometry by MS. Proc. Natl. Acad. Sci. U.S.A. 2005, 102, 3948-3953.

21. Gerber, S. A.; Rush, J.; Stemman, O.; Kirschner, M. W.; Gygi, S. P. Absolute Quantification of Proteins and Phosphoproteins from Cell Lysates by Tandem MS. Proc. Natl. Acad. Sci. U.S.A. 2003, 100, 69406945.

22. Kirkpatrick, D. S.; Gerber, S. A.; Gygi, S. P. The Absolute Quantification Strategy: A General Procedure for the Quantification of Proteins and Post-Translational Modifications. Methods 2005, 35, 265-273.

23. Ballif, B. A.; Roux, P. P.; Gerber, S. A.; MacKeigan, J. P.; Blenis, J.; Gygi, S. P. Quantitative Phosphorylation Profiling of the ERK/p90 Ribosomal S6 Kinase-Signaling Cassette and Its Targets, the Tuberous Sclerosis Tumor Suppressors. Proc. Natl. Acad. Sci. U.S.A. 2005, 102, 667-672.

24. Hinsby, A. M.; Olsen, J. V.; Mann, M. Tyrosine Phosphoproteomics of Fibroblast Growth Factor Signaling: A Role for Insulin Receptor Substrate-4. J. Biol. Chem. 2004, 279, 46438-46447.

25. Ibarrola, N.; Kalume, D. E.; Gronborg, M.; Iwahori, A.; Pandey, A. A Proteomic Approach for Quantitation of Phosphorylation Using Stable Isotope Labeling in Cell Culture. Anal. Chem. 2003, 75, 6043-6049.

26. Oda, Y.; Huang, K.; Cross, F. R.; Cowburn, D.; Chait, B. T. Accurate Quantitation of Protein Expression and Site-Specific Phosphorylation. Proc. Natl. Acad. Sci. U.S.A. 1999, 96, 6591-6596.

27. Goshe, M. B.; Conrads, T. P.; Panisko, E. A.; Angell, N. H.; Veenstra, T. D.; Smith, R. D. Phosphoprotein Isotope-Coded Affinity Tag Approach for Isolating and Quantitating Phosphopeptides in ProteomeWide Analyses. Anal. Chem. 2001, 73, 2578-2586.

28. Qian, W. J.; Goshe, M. B.; Camp, D. G., II; Yu, L. R.; Tang, K.; Smith, R. D. Phosphoprotein Isotope-Coded Solid-Phase Tag Approach for Enrichment and Quantitative Analysis of Phosphopeptides from Complex Mixtures. Anal. Chem. 2003, 75, 5441-5450.

29. Weckwerth, W.; Willmitzer, L.; Fiehn, O. Comparative Quantification and Identification of Phosphoproteins Using Stable Isotope Labeling and Liquid Chromatography/Mass Spectrometry. Rapid Commun. Mass Spectrom. 2000, 14, 1677-1681.

30. Ruse, C. I.; Willard, B.; Jin, J. P.; Haas, T.; Kinter, M.; Bond, M. Quantitative Dynamics of Site-Specific Protein Phosphorylation Determined Using Liquid Chromatography Electrospray Ionization Mass Spectrometry. Anal. Chem. 2002, 74, 1658-1664. 